\title{
Causes and consequences of the streambed restructuring of the Koiavgan Creek (North Caucasus, Russia)
}

\author{
Sergey Kharchenko ${ }^{1,2 *}$, Anatoly Tsyplenkov ${ }^{1,2}$, Dmitry Petrakov ${ }^{1}$, and Valentin Golosov ${ }^{1,2}$ \\ ${ }^{1}$ Faculty of Geography, Lomonosov Moscow State University, Leninskie Gory 1, 119991 Moscow, \\ Russian Federation \\ ${ }^{2}$ Institute of Geography, Russian Academy of Sciences, Staromonetny st. 29-4, 119017 Moscow, \\ Russian Federation
}

\begin{abstract}
The restructuring of the lower reach of the Koiavgan Creek channel (the right bank tributary of the Djankuat River) occurred on 1 July 2015 after continuous rainfall with a total precipitation amount of $227 \mathrm{~mm}$. This led to the breakthrough of the Djankuat Glacier lateral moraine. The lower reach of the creek channel was initially formed at the junction of the bedrock slopes and lateral moraine and descended sharply at the end of the moraine to a wide glacial valley of the Djankuat River. The part of the channel from the end of the moraine line to the creek's outlet in the bottom of the glacial valley had a height difference of $125 \mathrm{~m}$ at a distance of about $250 \mathrm{~m}$. The active landslide has been recorded in the place of future breakthrough based on interpretation of 2014 summer satellite image. The linear erosion began to form on the wall of the disruption. Thermokarst processes probably also contributed to this breakthrough. The total volume of sediment eroded during the breakthrough and for four years after is $156500 \mathrm{~m}^{3}$. The breakthrough has formed the largest sediment cone 300 meters wide and more than $200 \mathrm{~m}$ long in the bottom of the Djankuat River valley.
\end{abstract}

\section{Introduction}

Global climate change has had a dramatic impact on mountain glaciers around the world, and these glaciers in the Caucasus are no exception. The dominant trend is that Caucasian glaciers are slowly adapting to seasonal changes in total precipitation and higher air temperatures, showing a negative mass balance [1]. Similar situation is observed in the other mountains [2]. The widespread retreat of mountain glaciers is revealing new expanses of glacial debris, dynamics and fluvial transport of which are little understood [3]. In some areas the majority of sediment evacuation occurs during periods of enhanced melt water discharge [4]. In other cases, the large increase in suspended sediment load is due to the unusually warm summer [5]. However, sediment flux in the river catchments of proglacial

${ }^{*}$ Corresponding author: xar4enkkoff@yandex.ru 
zones is normally associated with summer rainstorms and melt-induced high water discharges. In some cases heavy rainstorms lead to formation of exceptional flood events, which significantly transform the mountain river channels [6]. This study aims to evaluate the consequences of extreme flood on the Koiavgan Creek and to identify the causes of channel restructuring.

\section{Study site}

The Koiavgan Creek is located in the Caucasus mountain (Russia), and belongs to the Djankuat River catchment being its right-bank tributary (Fig. 1). The main morphological characteristics and general information about lithology and landforms are presented in Table 1. Three small glaciers (Koyavgan, Viatau, and Visyachii) with total area $<0,5 \mathrm{~km}^{2}$ are located in the western part of the catchment. The meltwater draining from glaciers forms the Koiavgan stream and its tributary (Fig. 1), which flow into the Djankuat River. According to meteorological observations [7] the average daily precipitation (in water equivalent) is $11.2 \mathrm{~mm} \cdot$ day $^{-1}$ with a maximum of $97.2 \mathrm{~mm} \cdot$ day $^{-1}$. The most part of precipitation falls in the cold season in the form of snow. Air temperature ranges from -1.1 to $24.2^{\circ} \mathrm{C}$ with an average of $10.2{ }^{\circ} \mathrm{C}$ and from -9 to $17.6^{\circ} \mathrm{C}$ with a mean of $6.6^{\circ} \mathrm{C}$ near the mouth of the Koiavgan stream (2692 m a.s.1.) and at the glaciers (about $3000 \mathrm{~m}$ a.s.1.) respectively during ablation period (May-September). The catchment is completely covered with snow until late May - early June. At the beginning of July, only a few patches of snow remain at the highest elevations and north-facing slopes of the non-glaciated area. So, it is estimated that $98 \%$ of the total sediment flux occur during the ablation period [8].

\section{Methods}

Meteorological data were collected for the period 2007-2017 from State weather stations Cheget and Terskol which are located around the study site. Also, information about precipitation in the Djankuat valley bottom near the Koiavgan Creek mouth was taken from the database compiled by Rets et al. [7]. We used daily precipitation amount (in water equivalent). The local rain gauge was located $0.5 \mathrm{~m}$ above ground. Digital Elevation Model (DEM) of the lower reach of the Koiavgan Creek was developed based on aerial images. They were obtained using an unmanned aerial vehicle DJI Mavic PRO in September 2019. The resolution of the DEM is about $13 \mathrm{~cm}$. Total volume of sediment eroded since the breakthrough of the lateral glacial moraine by the Koiavgan stream in July 2017 was determined. The initial relief of the Koiavgan valley, lateral moraine and the bottom of the Djankuat River nearby the Koivagan Creek mouth on the moment preceding a breakthrough was restored based on combination of the DEM and high-resolution satellite image taken in 2014. It's possible to evaluate the total volume of sediment eroded by new channel of the Koiavgan Creek since July 2015 and more roughly to estimate the volume of sediments stored in the new delta of the Koiavgan Creek. The accuracy of the estimated volume of the delta was lower due to uncertainties in determining its boundaries at the bottom of the Djankuat River. In addition, the active landslide has been recorded in the place of future breakthrough based on interpretation of 2014 summer satellite image. Hydrological data including water and suspended sediment discharges in the upper reach of the Djankuat River for the 2015-2017 ablation season are also used for analysis (data was taken from the database [7]). 
Table. Some characteristics of the Koiavgan Creek catchment

\begin{tabular}{|c|c|c|}
\hline \multicolumn{2}{|c|}{ Characteristics } & Description \\
\hline \multicolumn{2}{|r|}{ Area, ha } & 300 \\
\hline \multicolumn{2}{|r|}{ Bedrocks } & $\begin{array}{l}\text { Galdorian metamorphic rocks (migmatites, gneisses) } \\
\text { with rare Ullucamian plutonic pegmatites by faults } \\
\qquad\left(\mathrm{gPR}_{2} \mathrm{gl} \text { with } \rho \mathrm{PZ}_{3} \mathrm{U}_{3}\right)\end{array}$ \\
\hline \multirow[t]{5}{*}{ Topography * } & Elevation range, $\mathrm{m}$ a.s.l. & $2692-3880$ \\
\hline & Elevation mean $\pm \mathrm{sd}, \mathrm{m}$ & $3329 \pm 209$ \\
\hline & Slope mean $\pm \mathrm{sd},{ }^{\circ}$ & $34,5 \pm 19$ \\
\hline & Slope $\max ,{ }^{\circ}$ & 82,6 \\
\hline & General aspect & SW \\
\hline \multicolumn{2}{|r|}{ Landforms } & $\begin{array}{l}\text { Bedrock monadnocks above cirques sloped surfaces with } \\
\text { subglacial moraine spots and the lateral moraine line in } \\
\text { the bottom of the catchment }\end{array}$ \\
\hline
\end{tabular}

* - on the Pleiades $1 \mathrm{~m}$ DEM data

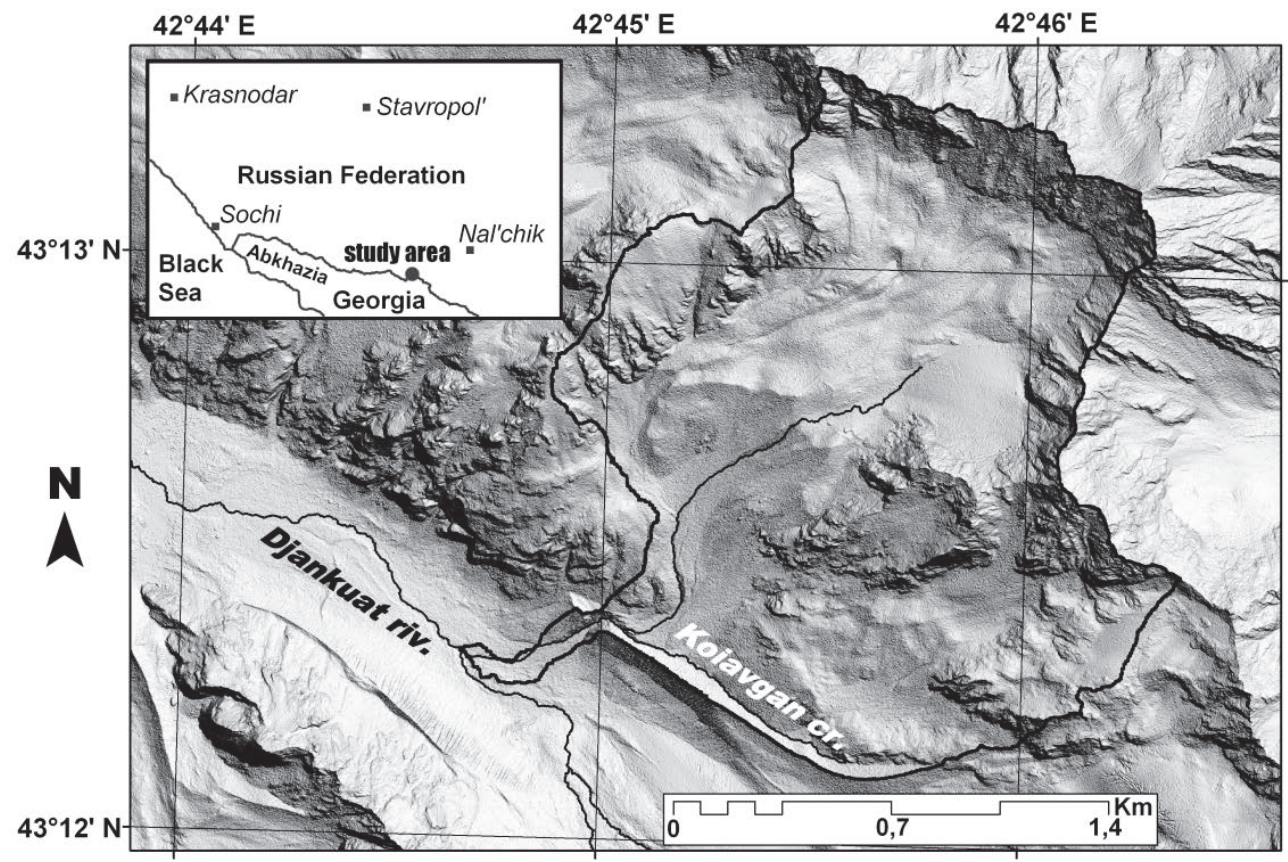

Fig. 1. Overview of the Koiavgan Creek and its location at the Caucasus.

\section{Results and discussion}

Results of field survey, analysis of satellite images and hydro-meteorological data allowed defining the key reasons of restructuring of the lower reach of the Koiavgan Creek. The location of the future breakthrough site in the glacial moraine was due to the formation of a small landslide on the moraine slope facing the Djankuat valley in the summer of 2014. It is possible that the thermokarst processes intensified on the landslide disruption wall. At the end of June and until July 1, 2015, the precipitation with a total layer of $227 \mathrm{~mm}$ fell in the Koiavgan catchment area over 7 days. In this case, the main cause of the breakthrough was apparently a supersaturation with water of the moraine deposits on the right bank of the 
stream. So, it was a combination of the several factors which lead to serious transformation of the creek channel.

Unfortunately, a maximum water discharge and turbidity were not fixed early morning on 1 July 2015. So, it is not possible to define the total volume of sediment which was transported by the Djankuat River downstream. The gauging station, located about $500 \mathrm{~m}$ downstream from the confluence of the Koiavgan Creek with the Djankuat River, was partly destroyed by the mudflow. However, sediment discharge was estimated based on results of water discharge measurement and turbidity samples taken few hours later after maximum discharge. It was calculated that at least 12000 tons of sediment were transported downstream for only 1 July 2015. This value exceeds the measured sediment transport for the whole ablation period in 2016 and 2017, which were 8649 tons and 10224 tons respectively. It is more likely that actual sediment transport for the given extreme event was much higher.

It was determined that the total volume of material eroded from the lateral moraine since the moment of the breakthrough is $156500 \mathrm{~m}^{3}$. The mean density of the moraine deposits is $2000 \mathrm{~kg} \cdot \mathrm{m}^{-3}$. So about 313000 tons of material was removed by the Koiavgan stream mainly in the moment of the breakthrough. The volume of the sediment cone (the new Koiavgan delta), which is appeared in the bottom of the Djankuat valley is $37100 \mathrm{~m}^{3}$. Its mass is roughly $75000-80000$ tons. Consequently, at least 220000 tons of material was redistributed along the bottom of the Djankuat River valley and transported downstream. Based on the the Djankuat River channel morphometry and the duration of the flood event on July, 12015 , it is possible to estimate, that approximately 40000 to 50000 tons of material were removed downstream. Parameters of the breakthrough didn't change considerably after the July 12015 event (Fig. 2). But active incision of the creek bed is still observed upstreams the breakthrough (Fig. 3). It leads to significant increase of the sediment discharge of the Djankuat River (in comparison with period before July 1, 2015).

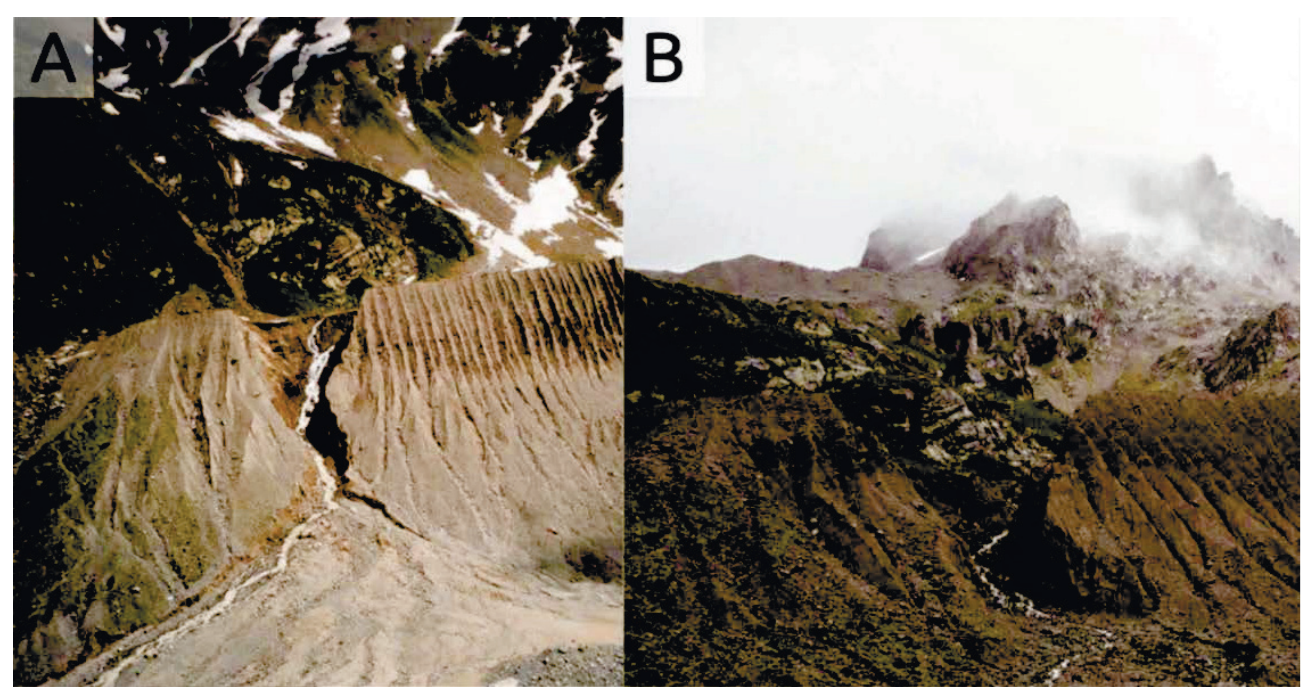

Fig. 2. View of the new lower reach of the Koiavgan Creek after the breakthrough: A - July 2015; B - July 2017.

It is very likely, that the intensity of incision directly depends on water discharge of the Koiavgan Creek. In turn, the water discharges in the river depend on the amount and intensity of rainfall. A significant amount of precipitation usually covers the entire altitude zone from 2000 to $3000 \mathrm{~m}$. This is illustrated by the example of a rainfall layers that were observed at the moment preceding the moraine breakthrough in the lower reach of the 
Koiavgan Creek (July $\left.1^{\text {st }}, 2015\right)$ and the outburst of Lake Bashkara (August $31^{\text {st }}, 2017$ ) on the three meteorological stations, located on the relatively small distance from the Djankuat River catchment (Fig. 4). Analysis of the available data at the Djankuat station allows us to make a number of preliminary conclusions regarding the frequency of days with rains with different daily rainfall. First, heavy rains with a layer of $50 \mathrm{~mm}$ or more are observed for at least once in two years. Secondly, extremely heavy rains with a daily layer of more than 80 $\mathrm{mm}$ are also not unique. Thirdly, the duration of the period with daily precipitation and the time of the heavy rainstorm within the ablation period are additional factors that must be taken into account when predicting the probability of formation of extreme runoff on the catchment.

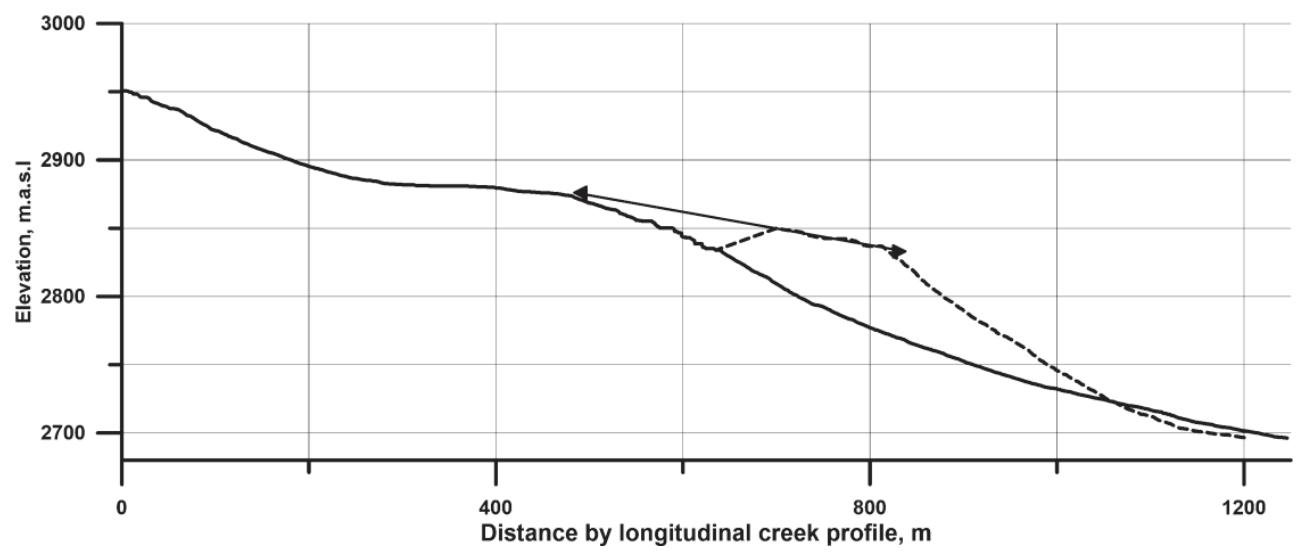

Fig. 3. Longitudinal profile of the Koiavgan Creek channel in September 2019 (measured, solid line) and in June 2015 (rebuilt from DEM, dashed line). The arrow shows the location of creek channel before the breakthrough (July $\left.1^{\text {st }}, 2015\right)$.

\section{Conclusion}

Heavy rain floods in the proglacial zone are associated with daily precipitation amount of more than $80-100 \mathrm{~mm}$. A similar situation can occur with moderate rainfall lasting several days. For example, 7-day rainfall with total precipitation amount of $227 \mathrm{~mm}$ was observed at the Koiavgan Creek catchment in the end of June 2015. This led to a breakthrough of the lateral moraine, which was located on the left side of the Koiavgan Creek in its lower reach. As a result, $156000 \mathrm{~m}^{3}$ of sediment was exported to the bottom of the Djankuat River valley. Only $20-25 \%$ of sediment was deposited on the sediment cone, which was recently the Koiavgan Creek delta. The remaining sediment volume was distributed along the bottom of the Djankuat River valley, and about $40000-50000$ tons were transported downstream by the Djankuat River. The sediment volume exported during this event corresponds to the total sediment volume exported by the Djankuat River (from the proglacial part of the catchment, including the Koiavgan catchment) for 4-5 years. The continued incision of the Koiavgan Creek channel (upstreams the breakthrough site) contributes to an increase in sediment runoff in the River Djankuat up to the present. It is possible to predict a fairly high repeatability of similar extreme floods in the catchments of the small proglacial rivers. According to meteorological observations, the frequency of heavy rainfall in this high-altitude zone of the central Caucasus is quite high. 


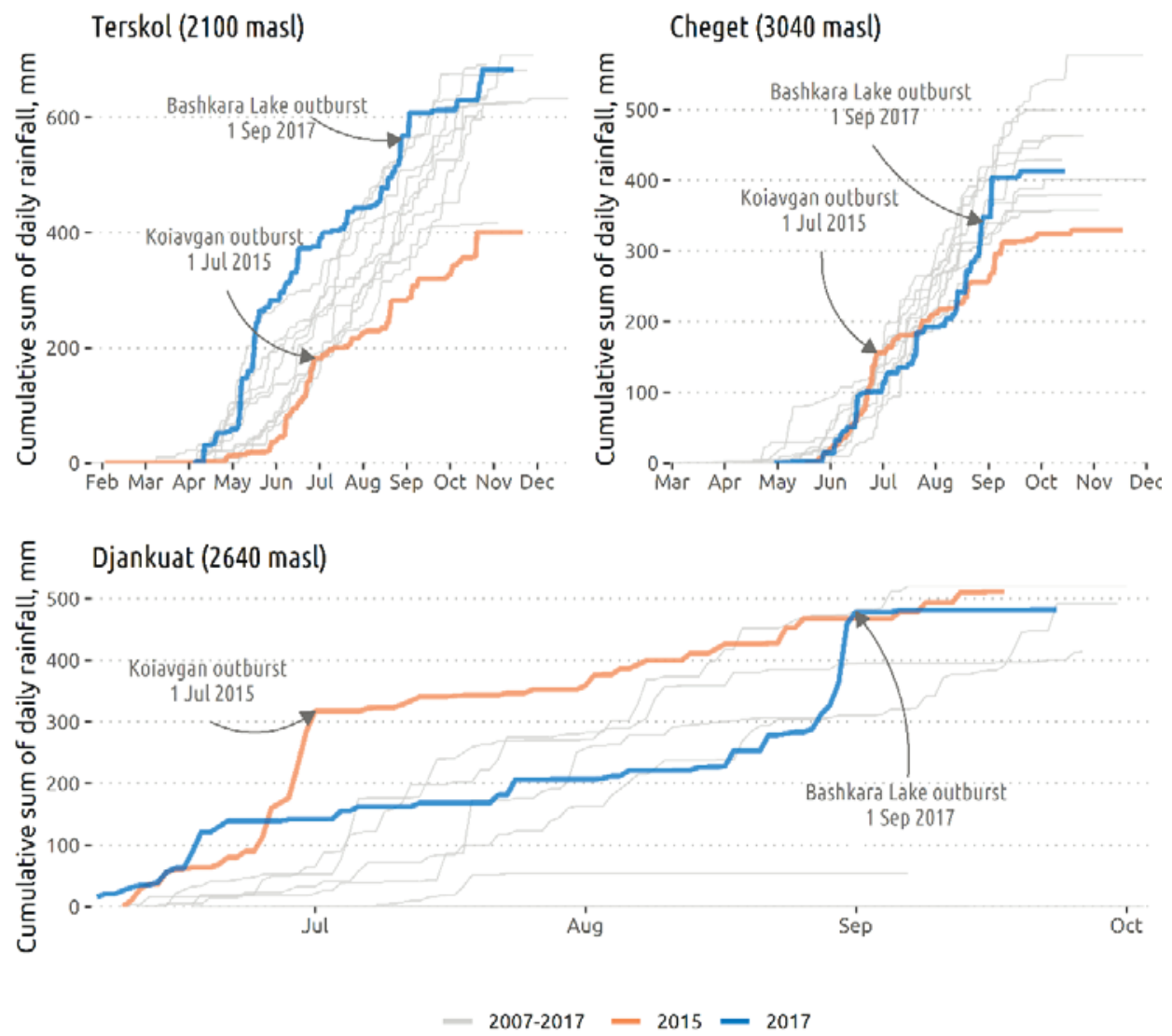

Fig. 4. Cumulative sum of the daily rainfall for ablation period for three meteorological stations, located in $30 \mathrm{~km}$ distance from the Djankuat River catchment: Terskol, Cheget and Djankuat.

The study was supported by Russian Science Foundation (project no.19-17-00181).

\section{References}

1. G.F. Nosenko, T.E. Khromova, O.V. Rototaeva, M.V. Shagedanova, Ice and Snow, 121, 1 (2013)

2. R.G. Barry, Prog.Phys. Geogr, 30 (2006)

3. L.A. Owen, G. Thackray, R.S. Anderson, J. Briner, D. Kaufman, G. Roe, W. Pfeffer, C. Yi. Geomorph. 58 (2004)

4. R. Hodgkins, R. Cooper, J. Wadham, M. Tranter Sedimentary Geol. 162 (2003)

5. T. A. Stott, N.J. Mount, J Hydrol. 332 (2007)

6. J.M. Turowski, E.M. Yager, A. Badoux, D. Rickenmann, P. Molnar, Earth Surf. Process.Landf.34 (2009)

7. E. Rets, V. Popovnin, P. Toropov, A. Smirnov, I. Tokarev, J. Chizhova, N. Budantseva, Yu. Vasil'chuk, M. Kireeva, A. Ekaykin, A. Veres, A. Aleynikov, N. Frolova, A. Tsyplenkov, A. Poliukhov, S. Chalov, V. Aleshina, E. Kornilova, Earth System Science Data, 11, 3 (2019).

8. M. B. Durgerov, V. S. Freindlin, L. P. Chernova, Materialy Glaciolologicheskih Issledovaniy, 19 (1972). 